\title{
Pedagogical Content Knowledge (PCK) Development in Statistics Teaching: What Content Knowledge does Mathematics Teachers have and Demonstrate during Classroom Practice?
}

\author{
S. B. ljeh \\ University of South Africa \\ ijehsb@unisa.ac.za
}

Doi:10.5901/mjss.2013.v4n14p191

\begin{abstract}
This paper presents the findings on mathematics teachers' pedagogical content knowledge (PCK) in statistics teaching. Six mathematics teachers were initially selected for the study based on their school's performance over two years in the senior certificate examination in mathematics, and the four top scorers in the a conceptual knowledge exercise (CKE) in statistics were finally selected for this study. The study adopted a qualitative research method. The data on the teachers' PCK were collected through lesson observations, questionnaires, interviews, video recordings, teachers' written reports, and document analyses. The results of the study show that the teachers possess topic specific subject matter content knowledge and use of procedural and conceptual knowledge to teach statistics in school mathematics. The implications for mathematics education programmes are discussed.
\end{abstract}

\section{Introduction}

Several researchers use the terms 'subject matter knowledge' and 'subject matter content' to describe the kind of knowledge that teachers need for teaching (Shulman, 1986; Ma, 1999; Vistro-Yu, 2003; Jong, 2003; Jong, Van Driel and Verloop, 2005; Halim and Meerah, 2002; Rollnick, Bennett, Rhemtula, Dharsey and Ndlovu 2008). In terms of mathematics teaching, Plotz (2007) refers to subject matter content knowledge as 'mathematical content knowledge'. With regard to PCK development in statistics teaching, it is necessary to define what each of the concepts means so that they can be used to define the PCK constructs used in statistics teaching. Plotz (2007) argues that mathematical content knowledge is largely acquired by studying mathematics in school, and this may be described as 'in-school acquired knowledge'. Van Driel, Verloop and De Vos (1998), Jong (2003), and Jong et al. (2005), describe subject matter knowledge as knowledge obtained through formal training at universities and colleges which may be regarded as disciplinary education. Subject matter knowledge, one can therefore conclude, is acquired through formal training in a subject area.

Ball and Bass (2000 argue that the subject matter knowledge needed by teachers is found not only in the topics of to be learned but also in the practice of teaching itself. In other words, knowing the content of a subject is not enough to qualify a teacher to teach; what makes a teacher capable of teaching is how well he or she facilitates learning. According to these authors, little is known about the way in which 'knowing' a specific topic in a list of topics affects a teacher's capabilities, and if one expects to identify the subject matter content knowledge needed for teaching from the curriculum without focusing on practice as well, not much will be gained (Ball and Bass, 2000; Plotz, 2007). Plotz's (2007) study also reveals that mathematical content knowledge and pedagogical knowledge are both required for effective teaching and can enhance development of PCK. He further stress that teachers' prior knowledge is also needed for effective content knowledge transformation and understanding since prior knowledge aids teachers in the design of problem solving activities during classroom practice.

Capraro, Capraro, Parker, Kulm and Raulerson (2005) researched the role of mathematics content knowledge in developing pre-service teachers' PCK using performance in a previous mathematics course, a pre- and post-test assessment instrument, success in the state-level teacher certification examination, and journals. Their study outlined the connection between mathematics content knowledge and pedagogical knowledge in developing PCK. A total of 193 undergraduate students in integrated method block courses were involved in the research project and the findings indicated that teachers' previous mathematical abilities are valuable predictors of students' success in teacher certificate examinations. In addition, mathematically competent pre-service teachers exhibited progressively more PCK since they 
had been exposed to mathematical pedagogy comprising subject matter content and teaching practice during their mathematics method courses. To be pedagogically effective in teaching a topic, it is necessary to have comprehensive understanding of it.

However, the South African mathematics (Grades 10-12) teaching force is made up mainly of practitioners who have three-year teaching diplomas obtained from the old (pre-1994) colleges of education (Rollnick et al., 2008). According to these authors less than $40 \%$ of these teachers hold a junior degree on the subjects they teach and mathematics content only measures up to that of first year at a university. In this study the key question is, given that the teachers show competence or understanding of these concepts in mathematics, irrespective of their training, how does this influence their teaching and therefore their PCK for teaching statistics in school mathematics?

\section{Conceptual framework}

According to Manouchehri (1976), subject matter content knowledge consists of an explanatory framework and the rules of evidence within a discipline. The subject matter content knowledge of prospective mathematics teachers is acquired primarily during disciplinary education (Jong, 2003). This knowledge consists of substantive content knowledge and syntactic content knowledge (Barnes, 2007). Substantive content knowledge refers "to the concepts, principles, laws, and models in a particular content area of a discipline (Barnes, 2007)." Syntactic content knowledge is the "set of ways in which truth or falsehood, validity or invalidity are established" (Schwab, 1978, cited in Shulman, 1986). In practice, teachers should not only be able to define the acceptable truths in a domain, but also to explain, in theory and in practice, why these truths are worth knowing and how they relate to other propositions in and outside the discipline.

Both types of subject matter knowledge (substantive and syntactic) are needed for teachers' development of PCK to create adequate understanding of the nature of the subject matter and how it should be taught (Jong, 2003). It is therefore assumed that mathematics teachers with good PCK have both types of subject matter content knowledge and are able to apply this knowledge in making the topic understandable to learners. This assumption is given empirical support by Wu (2005), who indicated that teachers with good PCK have a firm command of subject matter knowledge and are able to design instructional materials that allow learners to grasp what they teach. Muijs and Reynolds (2000) call them effective teachers.

Other scholars, such as Carpenter, Fennema, Petterson and Carey (1988), Even (1993), Manouchehri (1997), Van Driel et al. (1998), Halim and Meerah (2002), Tsangaridou (2002), Viri (2003) and Hill (2008) have studied the influence of subject matter knowledge on the PCK of pre-service, novice, and expert teachers. These studies reveal that teachers' content knowledge goes a long way towards determining the level of PCK. Subject matter content knowledge is a key components of PCK that was assessed in this study.

\section{Methodology}

The methodology for the study consisted of two phases. In the first phase, six identified mathematics teachers undertook a written exercise to assess their conceptual knowledge of statistics. The results of this exercise were used to select the four best-performing teachers for the second phase of the study.

The second phase consisted of a concept mapping exercise (CME), lesson observations, interviews, teachers' written reports, and document analyses to produce rich detailed descriptions of participating teachers' PCK in the context of teaching data-handling concepts at school level. The CME was used to indirectly assess content knowledge and the teachers' conceptions of the nature of school statistics and how it is to be taught. The qualitative data obtained were analysed to determine individual teachers' content knowledge, related pedagogical knowledge, and how they developed their PCK in statistics teaching. The analysis was based on iterative coding and categorisation of responses and observations in order to identify themes, patterns, and gaps in school statistics teaching. Commonalities and differences, if any, in the PCK profiles of the four participating teachers were determined and analysed.

The validity of the CKE was conducted by giving exercises to the teachers to ascertain whether CKE could be used to assess their knowledge of school statistics and to select participants for the study. A concept map was given to the same mathematics teachers to determine whether the CME would allow them to list topics according to Grades 10 , 11 and 12 and arrange them in logical order, such that one topic formed the basal knowledge of the next for each of the grades. Second, they were required to decide whether the memorandum was appropriate for answering the CME. The interview, questionnaire, and teacher written reports were validated by mathematics education experts using a set of criteria to establish whether these instruments contained appropriate information to determine teachers' mathematics 
educational background for developing subject matter content knowledge in statistics teaching (ljeh, 2013).

The reliability of the CKE was established through the Kuder-Richardson split half procedure (KR-20, KR-21). The reliability index was 0.81 . The CME and memorandum were given to four school mathematics teachers who did not participate in the study and who were physically located outside the study site to avoid contamination. There were consistencies in the responses of the mathematics teachers in the anticipated answers of the CME. The reliability of the teacher interviews, questionnaires, and written reports was determined by school mathematics teachers who were not involved in the study to determine the extent to which the instruments were likely to yield consistent responses (Cresswell, 2008) in terms of assessing the mathematics teachers' educational background that may have enabled them to develop their topic-specific PCK in statistics teaching.

\section{Result and Discussion}

Teacher A was observed teaching histogram construction and box-and-whisker plots in a step-wise fashion using the recommended mathematics textbooks and work schedule. For example, when he was asked, "What learning and teaching support materials do you use in teaching statistics?" he responded, "I use classroom mathematics textbooks recommended by the Department of Basic Education and the work schedule."

He started the lesson by asking the learners to name the components of measures of central tendency such as modes, medians, and means of ungrouped data to determine their prior knowledge of histogram construction. The learners responded: The components of measures of central tendency are mode, median and mean.

The components of measures of central tendency having been identified, the teacher and learners prepared a frequency table from the raw data. Using this table, the histogram was constructed by first drawing its horizontal and vertical axes (see Figure 1). The axes were labelled with data values on the horizontal axis, and frequencies on the vertical axis. A scale was chosen by the teacher, who stated that the highest and lowest values of the frequencies and data values, as well as the dimensions of the graph paper provided, had been considered. Next, the bars of the histogram were drawn by joining the line of best fit (see Figure 1). Teacher A's lesson showed that he had adopted a rule-oriented procedural approach to teaching histogram construction.

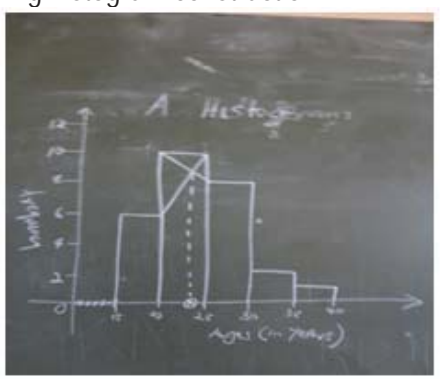

Figure 1: A histogram constructed by the teacher and learners during lesson

In teaching the construction of box-and-whisker plots, he gave further evidence of using procedural knowledge, focusing primarily on rules and algorithms, rather than conceptual knowledge. The procedural approach requires simply plugging the data into the appropriate formulae, and then working out the correct values of the quartiles for the box-and-whisker plots (see Figure 2). For example, using the formula; $Q_{1}=\frac{(n+1) t h}{4}$ to calculate the position of $Q_{1} ; Q_{1}=20 ; Q_{2}=23$ and $Q_{3}=$ 27, all the values were obtained from the ogive that the learners had been working on. The most challenging aspect for this teacher was knowing how to move from an algorithmic stage to a conceptually meaningful one as far as the students' learning was concerned.

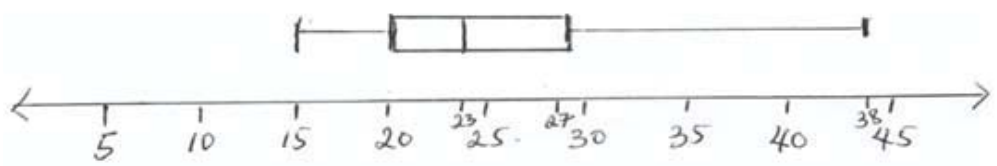

Figure 2: A box-and-whisker plot constructed with the values $\mathrm{Q}_{1}=20 ; \mathrm{Q}_{2}=23$ and $\mathrm{Q}_{3}=27$ 
However, he used a conceptual teaching approach during the lesson and demonstrated the mathematical connections and relationships between ogives and box-and-whisker plots by describing how quartiles were obtained from the ogive and used in the construction of the box-and-whisker plot (see Figure 2), the relationships between the ogive and boxand-whisker plot, and the calculation of the first, second, and third quartiles. A description of the number line on which the box-and-whisker was drawn, with its mathematical connections, were also elucidated during his lesson (see Figure 2). A conceptual-based instructional approach endeavours to provide the reasons that make algorithms and formulae work (Peal, 2010). The emphasis is placed on the learners' understanding of the relationships and connections between important statistical concepts such as the use of quartiles to construct the box-and whisker plots on a number line (see Figure 2). Overall, Teacher A implemented more of a rule-oriented procedural knowledge approach in teaching histogram and box-and-whisker plot construction than a conceptual one. To summarise, he used both knowledge approaches except that one was dominant.

Through non-verbal cues of nodding their heads, the learners indicated that they grasped the lesson on histogram construction through the use of conceptual knowledge better than when Teacher A adopted a rule-oriented approach. This observation was supported by the fact the learners were able to recall and apply the procedures posed by him. For example, the learners calculated the percentage of learners in the age group of (26-40) years as $37 \%$ using the frequency table and histogram that was constructed (Figure 1).

Teacher A's preference for the use of procedural knowledge in teaching histograms was confirmed in the learners' workbooks (document analysis) and during the interview. It was discovered that the learners had written down the teacher's rules or steps on how to construct histograms and box-and-whisker plots, as well as the diagrams of histogram and box-and-whisker plots. Teacher A might have adopted the use of procedural knowledge because the construction of histograms which demands that specific procedural rules must be followed, is consistent with a conceptual understanding of the term. In studies conducted by Flockton, Crooks and Gilmore (2004) and Leinhardt et al (1990) on graphing, they stress that the construction of graphs requires a sequence of drawing the axes, choosing the scale, labelling the axes, plotting the points, and joining the lines of best fit. The order of the steps, in the case of Teacher A, demonstrated the required knowledge and skills for histogram construction.

As observed, the learners experienced learning difficulties, particularly labelling the data axis with incorrect scales, which could mean that he possibly presented his lesson in a limited way, that is, solely procedurally, without providing the reasons underlying the procedures and clarifying the relationship between concepts (a conceptual knowledge approach) in histogram construction (see Figure 3).

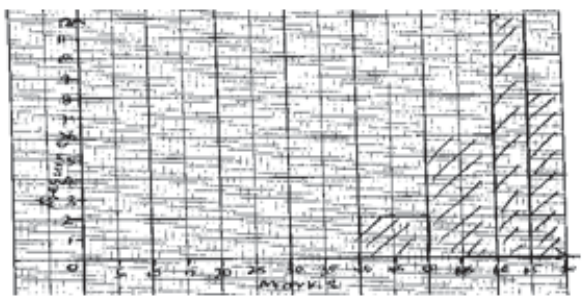

Fugure 3: An example of an incomplete classwork exercise on histogram construction due to incorrect scaling of the data axis.

During class work, the learners tried to draw a histogram, which could not be accommodated on the graph paper provided because they scaled the data axis incorrectly (see Figure 3). It may be said that Teacher A's PCK in terms of subject matter content knowledge presentation did not always reveal the required variety of ways of presenting the data handling topics to his learners for ease of access. In some instances, he demonstrated the use of both procedural and conceptual knowledge in teaching histograms and box-and-whisker plots, but he predominantly used a set of algorithms to demonstrate graph construction. In the main lesson on histogram and box-and-whisker plots, he displayed factual knowledge, procedural proficiency, and conceptual understanding of the data handling topics that were taught.

\subsection{Teacher $B$}

Teacher B planned and taught his statistics lessons on bar graphs and ogives from the recommended mathematics textbooks and work schedules. He used a predominantly rule-driven formal procedural approach to statistical graphs (see Figure 4). As observed, in starting his lessons he tried to identify learners' prior knowledge of the new topic. For 
instance, he introduced bar graph construction and interpretation with a pre-activity that assessed learners' understanding of the way in which to prepare a frequency table. For example he asked, prepare a frequency table of the following scores: $2,3,4,5,5,6,4,7,5,6$. His use of pre-activities as diagnostic strategies to identify learners' preexisting knowledge was also attested to in his responses to the teacher interview, questionnaire, and written reports.

Teacher B taught graphical constructions of bar graphs and ogives according to the learning outcomes of data handling as stated in the mathematics curriculum (DoBE, 2010). These outcomes require that learners should be able to use appropriate measures of central tendency and spread to collect, organise, analyse, and interpret data, in order to establish statistical and probability models for solving related problems (DoBE, 2011). Teacher B followed precisely the order in which the learning outcomes were stated in teaching his learners how to construct bar graphs and ogives. In practice this meant, as observed in his lesson, drawing the axes, choosing the scale, labelling the axes, plotting the points, and joining the line of best fit - in that order (see Figure 4). Teacher B demonstrated his PCK for drawing bar graphs in line with the sequence described.

Flockton et al (2004) confirm that for a person to understand a graph, he or she should be able to use the construction skills of drawing the axes, labelling the axes, plotting the points, and joining the line of best fit to construct a graph.

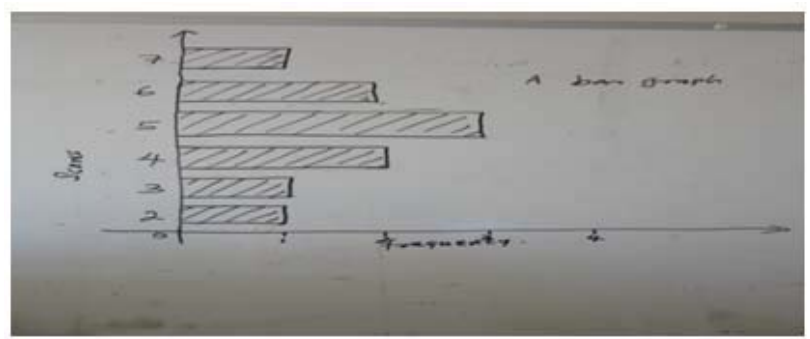

Figure 4: Bar graph of the scores of learners in test on how to construct, analyse, and interpret a bar graph

Teacher B's assumed PCK on bar graphs and ogive constructions could be characterised as procedural in terms of his lesson planning and teaching approach. Teacher B's predominant use of a formal procedural approach was also triangulated in the analysis of his learners' workbooks (document analysis). The learners drew the bar graph and wrote down the teacher's steps on how to construct bar graphs and ogives. Teacher B might have been influenced to adopt a formal procedural approach because of the learning outcomes of data handling as laid down in the Curriculum and Assessment Policy Statement (CAPS) (DoBE, 2012). Besides, the construction of bar graphs and ogives demands specific procedural rules (Flockton et al, 2004 and Leinhardt et al, 1990).

Having said that, when the teacher merely taught them the rules for constructing bar graphs, some learners experienced misconceptions, confusing bar graphs with histograms, and histograms with ogives. Teacher B can be said to have presented his lesson in a limited way with insufficient explanations of how to choose the scales of grouped data (consisting of histogram, frequency polygon, ogive, and scatter plot) that are used to analyse and interpret large data. Further, Teacher B seems not to have the flexibility to present the topics to the learners in different ways because his lessons were presented solely according to a procedural knowledge approach.

A detailed description of the construction of bar graphs and ogives using a conceptual knowledge approach would have been ideal in presenting the lesson and would have avoided possible misconceptions and learning difficulties that the learners encountered in the lesson. Conceptual knowledge involves understanding mathematical ideas and procedures and includes basic arithmetic facts (Engelbrecht, Harding \& Potgieter, 2005). It is rich in relationships among important mathematical concepts such as calculating the quartile positions and locating the quartile itself on the ogive, class intervals and boundaries, frequencies, and cumulative frequencies of an ogive. But Teacher B's teaching of bar graphs and ogives was dominated by a procedural knowledge approach which involves following a rule or procedure without a detailed explanation of the relationships and mathematical connections between the concepts being learned, such as calculating a quartile position and locating it in an ogive. Thus, the teacher is probably unable to present his lesson in a variety of ways to ensure better comprehension and understanding.

Baker et al (2001) and Bornstein (2011) note that a teacher who is unable to present mathematics content to learners in a variety of ways tends to expose them to learning difficulties, such as constructing a histogram instead of an ogive because of the use of an incorrect scale for labelling the data axis as was observed during the lesson on ogives. A 
combined approach of both procedural and conceptual knowledge would have helped to deepen the learners' understanding and would have avoided the misconceptions and learning difficulties that the learners had developed during the lesson, as suggested by Engelbrecht, Harding \& Potgieter (2005).

\subsection{Teacher C}

Teacher $\mathrm{C}$ also displayed evidence of a procedural rather than a conceptual knowledge approach in his lessons on the construction of ogives and scatter. Repetition. Schneider and Stern (2010) view conceptual knowledge as mastery of the core concepts and principles and their interrelations in the mathematics domain; knowledge rich in relationships. On the other hand, procedural knowledge can be viewed as consisting of rules and procedures for solving mathematics problems. Procedural knowledge in mathematics allows learners to solve problems quickly and efficiently because it is to some extent automated through drill work and practice.

Teacher $\mathrm{C}$ demonstrated the requisite knowledge of and skills for constructing ogives and scatter plots in a stepby-step manner. For example, in his teaching on ogives, he moved from algorithmic to a conceptually meaningful stage. He began his lesson on ogives by trying to identifying the learners' prior knowledge of the concept of ogives through oral questioning, and the accuracy of the homework on histograms that had previously been taught (see Figure 5). Subsequently, using a cumulative frequency table prepared by the learners, an ogive was constructed by first drawing its horizontal and vertical axes. The data values were labelled on the horizontal axis (the upper class boundaries), and the cumulative frequencies on the vertical axis (see Figure 5). A scale was chosen by the teacher, who indicated that he had chosen it by considering the highest and lowest values of the frequency and data values. The points were plotted and the line of best fit was joined to produce the ogive (see Figure 5).

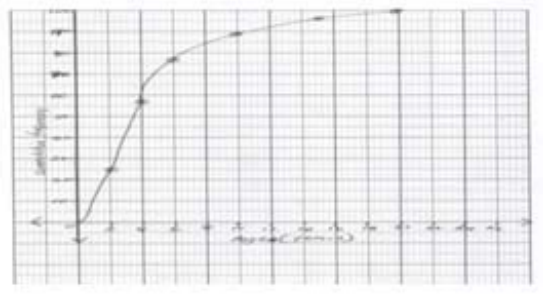

Figure 5: An Ogive of age distribution of sample of 100 cars owners park in a car park

This process of constructing an ogive from grouped data depicted a rule-oriented procedural approach. His procedural knowledge in teaching ogives (which was understandable to his learners) is believed to have been developed as a result of five years' mathematics teaching experience, and using the recommended lesson plan and work schedule of the Department of Education (DoE, 2010). The same procedural approach was used to teach scatter plots. Some of the factors that may have contributed to Teacher $\mathrm{C}$ teaching scatter plots in a step-wise manner, following a particular order or sequence, could be attributed to the way in which the learning outcome of data handling is stated in the mathematics curriculum (DoBE, 2010). The document indicates that competency in graphing requires that the learner is able to construct, analyse, and interpret statistical and probability models to solve related problem. The construction of graphs, as stated, entails scaling, drawing axes, labelling the axes, plotting points, and joining the line of best fit (Flockton et al, 2004; Leinhardt et al, 1990). Teacher C followed this sequence for teaching scatter plots. In the lesson he gave a full explanation of how to construct a scatter plot before demonstrating how to analyse and interpret it. The learners did their classwork in groups. They were presented with exercises on scatter plots, and were requested to analyse and interpret the plots to determine whether there was a correlation between the variables $X$ and $Y$.

Teacher C's preferred procedural approach to teaching the topic was confirmed in the learners' workbooks, portfolios, teacher interview, and written reports. Owing to the limited use of conceptual rather than procedural knowledge - namely knowledge of the core concepts and principles and their interrelations in teaching ogive and scatter plots, some learners displayed misconceptions and learning difficulties in their analysis and interpretation of scatter plots. For example, a negatively correlated linear scatter plot was interpreted by the learners as having no correlation because of an outlier that lay far from the line of best fit (see Figure 6). 


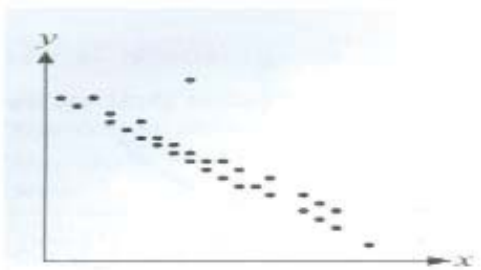

Figure 6: A negatively correlated scatter plots

This misconception could be attributed to the rule-oriented approach that had been adopted to describe the construction of scatter plots which did not allow for sufficient explanation of the interrelationships among the data values, frequencies, lines of best fit, and outliers (ljeh, 2013). The learning difficulty of interpreting a negatively correlated scatter plot as having no correlation owing to outliers may further indicate that in teaching construction of scatter plots the teacher did not explain an outlier, line of best fit, type and nature of correlation, and how the presence of an outlier affects the correlation of the $X$ and $Y$ variables of the scatter plot.

What can be gleaned from the discussion so far is that teachers need to possess deep conceptual understanding of the mathematics concepts that they are teaching and must be able to illustrate why mathematical algorithms work and how these algorithms can be used to solve problems in real-life situations (Nicholson \& Darnton, 2005). The learning difficulties experienced by the learners were subsequently addressed by Teacher $C$ during post-activity discussions (instructional strategy); a strategy that was frequently used by him during his lessons on ogives and scatter plots.

An important task of any teacher is to attempt to transform the content to be taught in such a way as to make it comprehensible to learners (Mohr \& Townsend, 2002). Teacher C also displayed evidence of a conceptual approach by providing the reasons that make the algorithm and formula work, and by explaining the relationships between important statistical concepts as well as the mathematical connection between them during the lessons on ogives. It was significant that more learners seemed to possess a better grasp of the topic and were able to construct and interpret ogives by means of this approach rather than a procedural one. In the particular lessons observed, Teacher $\mathrm{C}$ explained the mathematical connections and relationships between quartile positions and the quartiles and how quartiles can be used to interpret ogives. In doing so, Teacher $\mathrm{C}$ could be regarded as having displayed adequate subject matter content knowledge of school statistics.

\subsection{Teacher D}

In Teacher D's observed lessons, it was noted that he had planned and taught his lessons on bar graphs and histograms using the Department of Basic Education's mathematics work schedule, and the recommended textbooks as sources of information. This was confirmed in the teacher questionnaire and interview. For instance when he was asked, "What learning and teaching support materials do you use in teaching statistics?" Teacher D responded, "I use classroom mathematics by Laridon et al, 2006 and the work schedule."

During his teaching of bar graph and histogram construction, he used more of a procedural approach to teaching bar graphs and histograms than a conceptual one. For example, Teacher D taught the lesson on bar graphs in a step-bystep manner, beginning with pre-activities to identify the learners' prior knowledge of bar graph construction, followed by the preparation of a frequency table compiled by the learners using a familiar daily life example (see Figure 7). In this case, a frequency table was prepared of the number of cars in a car park according to their make. Next, with the help of the frequency table, a bar graph was constructed by drawing its horizontal and vertical axes and labelling them appropriately. A scale was chosen by the teacher with the explanation that this was done by considering the highest and lowest values of the frequencies and the companies that manufactured the cars. Next, the points were plotted and the line of best fit was joined to produce the bar graph (see Figure 7). The teacher's specific strategy for teaching bar graph construction followed a rule-oriented procedural approach using procedural knowledge. 


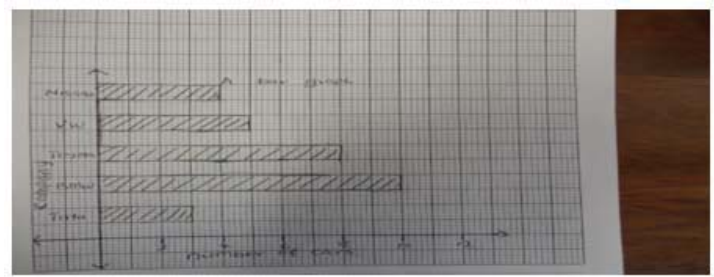

Figure 7: A Bar graph showing the numbers of makes of cars in a car park

Engelbrecht et al (2006) describe the procedural knowledge approach as "following a rule or procedures flexibly, accurately, efficiently and appropriately in completing a given task". For example, in constructing a statistical graph, a procedural knowledge approach requires a series of actions such as drawing the axes, choosing the scale, labelling the axes, plotting the points, and joining the line of best fit. But what may sometimes be challenging is knowing how to move from the procedural stage to a conceptually meaningful one in terms of student learning.

As with the other teachers, Teacher D's procedural knowledge may have been developed over his 15 years of teaching mathematics in high school, using the recommended lesson plan and work schedule for statistics (DoBE, 2010). It could be suggested that although Teacher $D$ possesses adequate ways of presenting bar graph construction to his learners, his PCK may be limited in the sense that he presented his lesson procedurally, an approach that was not always responsive to the learners' needs. Consequently, some of the learners constructed the classwork task without leaving spaces between the bars of the graph. The inability to consider the consistency of spaces between the bars of a graph during lesson presentation resulted in learning difficulties during classroom practice.

According to Shulman (1987), representation involves a teacher thinking through key ideas and identifying alternative ways of presenting them to learners. It is a stage in which suitable examples, demonstrations and explanations are used to build a bridge between the teacher's comprehension of the subject matter and what is required for the learners (Ibeawuchi, 2010). Multiple forms of representations are highly desirable if one is to be successful in the teaching process (Rollnick et al, 2008). Teacher D, in certain graphing topics, displayed evidence of an alternative conceptual knowledge approach in teaching histograms. Engelbrecht et al (2005) describe a conceptual knowledge approach as "involving an understanding of mathematical ideas and procedures consisting of the knowledge of basic arithmetic facts". It is knowledge rich in relationships and understanding of important statistical concepts in bar graph and histogram constructions. In the lesson observed, Teacher D explained in detail the meaning of a histogram. According to him, "a histogram is a graphical representation, showing a visual impression of the distribution of grouped data. It consists of tabular frequencies shown as adjacent rectangular bars, erected over discrete intervals, with an area equal to the frequency of the observations in the interval. Unlike the bar graph, a histogram is used to represent a large set of data (e.g. a population census) visually, but with no spaces between the bars". His conceptual approach (presumably PCK) to teaching the construction of a histogram enhanced conceptual understanding of the topic as the learners seemed to be satisfied with Teacher D's conceptual explanation of how to construct a histogram after they had experienced misconceptions and learning difficulties in labelling the data axis. They displayed non-verbal cues of nodding their heads in agreement with the teacher's explanation.

From the lessons observed with Teacher $\mathrm{D}$, he used a procedural rather than a conceptual knowledge approach. His preferred use of this approach was confirmed in the document analysis of the learner workbooks and written reports. The learners had completed the diagrams on bar graphs and histograms efficiently, with indications of the procedures that had been adopted in constructing these statistical graphs. Star (2002) argues that it is important for practising teachers to possess both kinds of knowledge in order to impart teaching to the learners in a meaningful way. The use of both a rule-oriented procedural and a conceptual knowledge approach reveals that teachers are looking for ways of making the teaching of bar graphs and histograms comprehensible and accessible to their learners. Moreover, the construction of graphs demands that a particular order of actions should be followed, consistent with conceptual understanding. Teacher $\mathrm{D}$ can therefore be said to possess and demonstrate the required knowledge of bar graph and histogram construction.

\section{Conclusion and Recommendation}

The four participating teachers taught statistical graphs predominantly using procedural knowledge and less frequently conceptual knowledge. The use of procedural knowledge was to some extent dictated by the nature of the topic which 
requires learners to be able to collect, organise, analyse, and interpret statistical and probability models to solve related problems (DoBE, 2010). A second factor that leads to the use of procedural knowledge is the way in which statistical graphs should be constructed which involves drawing axes, choosing scales, labelling axes, plotting points, and joining the lines of best fit. Other ways in which the teachers demonstrated the subject matter content knowledge they possess, included the frequent use of mathematics textbooks and CAPS documents. They develop additional subject matter content through using the above-mentioned resources and attending content knowledge workshops. This study has provided a critical analysis of the PCK (subject matter content knowledge) that the selected mathematics teachers demonstrated during the teaching of statistics to enhance continuous improvement in the development of teacher education programmes for in-service and pre-service mathematics teachers.

\section{References}

Ball, D.L. \& Bass, H. (2000). Interweaving content and pedagogy in teaching and learning to teach: knowing and using mathematics. In J. Boaler (ed.)2000. Multiple perspectives on mathematics teaching and learning. Westport, Conn.: Ablex, 83-104.

Ball, D.L., Thames, M.H. \& Phelps, G. (2008). Content knowledge for teaching. What makes it special? Journal of Teacher Education, $59(5), 589-607$.

Baker, R.S., Corbett, A.T. \& Koedinger, K.R. (2001). Toward a model of learning data representation. Proceedings of the Twenty-third Annual Conference of the Cognitive Science Society. University of Edinburgh, Scotland.

Barnes, H.E. (2007). The relationship between the subject matter knowledge of secondary pre-service mathematics teachers and classroom practice. PhD thesis, University of Pretoria.

Bornstein, D. (2011). A better way to teach mathematics. Opinionator.

Carpenter, T.P., Fennema, E., Peterson, P. \& Carley, D.A. (1998). Teachers' pedagogical content knowledge of students' problem solving in elementary mathematics. Research in Mathematics Education, 24(2),94-116.

Capraro, R. M., Carpraro, M. M., Parker, D., Kulm, G. \& Raulerson, T. (2005). The mathematics content knowledge role in developing pre-service teachers' pedagogical content knowledge. Journal of Research in Childhood Education 20 (2), 1-118.

Creswell, J. W. (2008). Educational research: Planning, conducting, and evaluating quantitative and qualitative research.

Department of Basic Education (2010). Curriculum and Assessment Policy Statements for Mathematics (CAPS). Pretoria: Government Printer.

Department of Basic Education (2011). Curriculum and Assessment Policy Statements for Mathematics (CAPS). Pretoria: Government Printer.

Department of Basic Education (2012). Curriculum and Assessment Policy Statements for Mathematics. Pretoria: Government Printer.

Department of Basic Education (2012). Report on the National Senior Certificate Examination. National Diagnostic Report on Learners Performance. Pretoria: Government Printer.

Department of Education (2011). Status of the language learning and teaching reports. Pretoria: Government Printer.

Engelbrecht, J., Harding, A. \& Potgieter, M. (2006). Undergraduate students' performance and confidence in procedural and conceptual mathematics. Pretoria: University of Pretoria Press.

Flockton, L., Crooks, T, \& Gilmore, A. (2004). Graphs, tables and maps: Assessment results 2003. Dunedin: Educational Research Unit, University of Otago.

Halim, L. \& Meerah, S.M. (2002). Science trainee teachers' pedagogical content knowledge and its influence on physics teaching. Research in Science and Technological Education, 20(2), 215-225.

Hill, H.C. (2008). Unpacking pedagogical content knowledge: Conceptualizing and measuring teachers' topic-specific knowledge of students. Journal for Research in Mathematics Education, 39(4), 372-400.

Ibeawuchi, O.E. (2010). The role of pedagogical content knowledge in the learning of quadratic functions. MEd thesis. Pretoria, University of South Africa.

ljeh, S. B. (2013). How competent mathematics teachers develop pedagogical content knowledge in statistics teaching. PhD thesis. University of Pretoria, Pretoria, South Africa.

Jong, O.D. (2003). Exploring science teachers' PCK. In D. Psillos, P. Karotoglou, V. Tselfes et al. (eds). Science education research in the knowledge-based society. Dordrecht: Kluwer Academic, 373-381.

Jong, O.D., Van Driel, J.H. \& Verloop, N. (2005). Preservice teachers' pedagogical content knowledge of using particle models in teaching chemistry. Journal for Research in Science Teaching, 42(8), 947-964.

Leinhardt, G., Zaslavsky, O. \& Stein, M.K. (1990). Functions, graphs, and graphing: Tasks, learning and teaching. Review of Educational Research, 60(1) (Spring), 1-64.

Ma, L. (1999). Knowing and teaching mathematics: Teachers' understanding of fundamental mathematics in China and the United States. Mahwah, NJ: Erlbaum.

Manouchehri, A. (1997). School mathematics reform: Implementations for mathematics teacher preparation. Journal of Teacher Education, 48(3), 197-209.

Mohr, D.J. \& Townsend, J.S. (2002). Research to practice: Using comprehensive teaching models to enhance PCK. Teaching Elementary Physical Education, 13(4), 2-6. 
Muiis, D. \& Reynolds, D. (2000). School effectiveness and teachers' effectiveness in mathematics: Some preliminary findings from evaluation of the mathematics enhancement programme (primary). School Effectiveness and Improvement, 11(3), 273-303.

Plotz, M. (2007). Criteria for effective education with regards to mathematical content knowledge for teaching. PhD dissertation. Potchestroom Campus, North-West University.

Rollnick, M., Bennett, J., Rhemtula, M., Dharsey, N. \& Ndlovu, T. (2008). The place of subject matter knowledge and pedagogical content knowledge: A case study of South African teachers teaching the amount of substance and chemical equilibrium. International Journal of Science Education, 30(10), 1365-1387.

Schneider, R.M. \& Plasman, K. (2011). Science teacher learning progressions: A review of science teachers' pedagogical content knowledge development. Review of Educational Research, 20(10), 1-37.

Shulman, L.S. (1986). Those who understand: Knowledge growth in teaching. Educational Researcher, 15, 4-14.Sirohi, V. (2004). A study of underachievement in relation to study and attitudes. Journal of Indian Education, 14, 1-8.

Star, R.J. (2002). Re-conceptualizing procedural knowledge: Flexibility and innovation in equation solving. Paper presented at the annual meeting of the American Educational Research Association (AERA), New Orleans, Louisiana: April 2002.

Mathematics teachers at work: Connecting curriculum materials and classroom instruction. New York: Routledge.

Van Driel, J., Verloop, N. \& De Vos, W. (1998). Developing science teachers' pedagogical content knowledge. Journal for Research in Science Teaching, 35(6), 673-695.

Vistro-Yu, C.P. (2003). On pedagogical knowledge in mathematics: How secondary school mathematics teachers face the challenge of teaching a new class. Quezon City, Philippines: Ateneo de Manila University,

$\mathrm{Wu}, \mathrm{H}$. (2005). Must content dictate pedagogy in mathematics education? Expanded version of a talk given at California State University, Northridge, 27 October 2004. 